\title{
Development of Fiber-Optic Current Sensing Technique and Its Applications in Electric Power Systems
}

\author{
Kiyoshi KUROSAWA* \\ 4-15-16, Jindaiji-Motomachi, Chofu-shi, Tokyo 182-0017, Japan \\ *Corresponding author: Kiyoshi KUROSAWA_Ｅ-mail: kurosawa.kiyoshi@mist.dti.ne.jp
}

\begin{abstract}
This paper describes the development and applications of a fiber-optic electric current sensing technique with the stable properties and compact, simple, and flexible structure of the sensing device. The special characteristics of the sensors were achieved by use of the special low birefringence fiber as the Faraday-effect sensing element and were also achieved with creation of sensing schemes which matched with the features of the fiber. Making use of the excellent features of the sensing technique, various current monitoring devices and systems were developed and applied practically for the control and maintenance in the electric power facility. In this paper, the design and performance of the sensing devices are introduced first. After that, examples of the application systems practically applied are also introduced, including fault section/point location systems for power transmission cable lines.
\end{abstract}

Keywords: Current, sensor, fiber, Faraday-effect, power, application

Citation: Kiyoshi KUROSAWA, "Development of Fiber-Optic Current Sensing Technique and Its Applications in Electric Power Systems," Photonic Sensors, 2014, 4(1): 12-20.

\section{Introduction}

Electric current measurement is a basic and important technique for the control and supervision in most facilities sustaining industry and community, such as the power facility. Traditionally, the current transformers consisting of iron cores and windings have been mainly used for the measurement. However, the followings are recognized as problems of the device:

(1) Current transformers are heavy and bulky.

(2) It is difficult to install them to thick and/or high voltage conductors and also is difficult to install them in the existing apparatus.

(3) The measurement signals are influenced by the electromagnetic induction noise.

(4) It is difficult to measure the large current, especially the low frequency component, which flows in a power system under the accident condition.

In the 1960s, as a hopeful solution for the problems, the optical current sensing method applying the Faraday-effect was proposed [1]. Since then, the research and development of the current sensing technique using the proposed principle has been carried out in many institutes worldwide. In the earlier period of the development, balk type sensing elements such as a glass block were used. However, after that, a method using the optical fiber as the Faraday sensing element, "optical fiber current sensor", has been studied and developed [2]. In 
recent years, with the help of the results of the activities worldwide, the practical use of the technology has been progressing.

This paper describes the development and practical application of a fiber-optic current sensing technique, carried out by the author and his colleagues in Tokyo Electric Power Company (TEPCO), in cooperation with several companies. By using the developed sensing devices, accurate current monitoring can be done easily by simply winding the flexible sensor fiber around the current conductor. Several kinds of applications of the sensor have been realized utilizing the advantageous characteristics.

In this paper, firstly, the developed sensing techniques, i.e. configuration and operation of the sensing device, key techniques to achieve good sensing characteristics, performance of a device, are described. Then, principal examples of functional systems applying the sensing devices are introduced from a viewpoint of practical applications.

The development results introduced in this paper are those of activities carried out until 2012, since the author retired from TEPCO in 2012.

\section{Sensing technique}

\subsection{Configuration, operation, and performance [3-6]}

Figure 1 shows the schematic configuration of the optical fiber current sensing device, reflection type, developed for the alternating current (AC) current measurement. Figure 2 is an appearance of a model of the sensing device. In Fig. 1, the wideband light is transmitted from the source (ASE, $1550 \mathrm{~nm}$ band) to the "optical box" (composed of optical crystals, a lens, and other components) with a signal transmission fiber (silica, single mode). In the optical box, the polarization of the light is transformed to linear polarization by a polarizer, and the linearly polarized light launches into the sensing fiber (special fiber made from the low birefringence flint glass, mentioned later) [6]. The inserted light is reflected by a mirror set at the other end of the fiber and transmitted back to the optical box. In the sensor fiber, the Faraday-effect occurs by the application of the magnetic field induced around the current to be measured. Then, the light passing through the fiber is inserted into an analyzer in the optical box and is split into two beams whose directions of polarization are orthogonal each other. In this scheme, the intensity of the two light beams is modulated responding to the Faraday-rotation. In order to obtain the good linearity between the light intensity modulation and the Faraday-rotation angle, 45-degree optical bias for the polarization angle of light is set in the optical box with a magnetic garnet crystal $[3,7]$. The two beams of the modulated light from the analyzer are sent back to the electronic circuit with the signal transmission fibers and converted to electrical signals by photo detectors (PDs). Finally, in the signal processing circuit, the intensity modulation of each signal is calculated, and then, the averaging value of the two modulations is obtained as the output voltage, which is proportional to the current to be measured $[3,4]$. Current to be measured

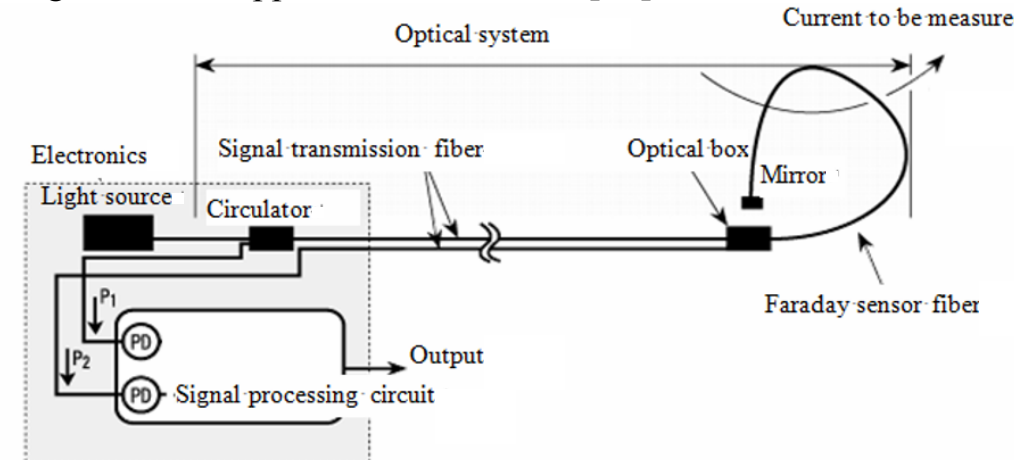

Fig. 1 Schematic configuration of reflection type optical fiber current sensor. 


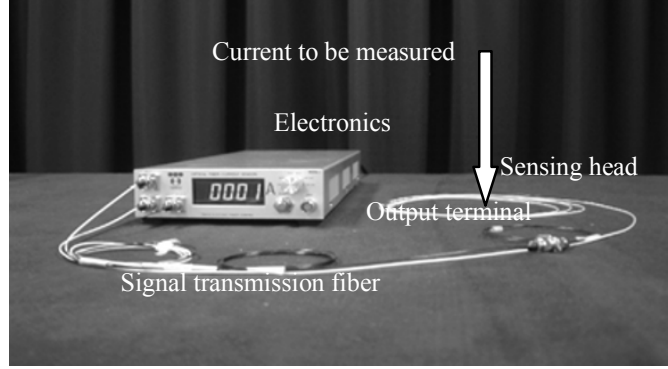

Fig. 2 A set of the reflection type current sensing device.

Figure 3 shows the block diagram of the signal processing circuit.

By using this device, when the sensing fiber is a closed loop interlinked with the current to be measured, based on the Ampere's law, the Faraday-rotation angle is precisely proportional to the current, without relation to the shape of the fiber loop or position of the current conductor.

Performances of the model are as follows. The output voltage is in the range of $-10 \mathrm{~V}$ to $+10 \mathrm{~V}$. The maximum current to be measured is $6.4 \mathrm{kA}$. The frequency response band is between $3 \mathrm{~Hz}$ and $10 \mathrm{kHz}$ $(-3 \mathrm{~dB})$. The non-linearity is $-0.16 \%$ for $6.4 \mathrm{kA}$. The noise included in the output voltage is equivalent to 1 Arms of the measured current. The usable temperature range of the sensing head is from $20{ }^{\circ} \mathrm{C}$ to $+80{ }^{\circ} \mathrm{C}$. The dependence of the output value on temperature around the sensing head is in the range of $-0.2 \%$ to $+0.2 \%$ [5]. The maximum length of the sensor fiber is about $5 \mathrm{~m}$. The maximum distance of signal transmission is nearly $20 \mathrm{~km}$. The power source voltage is in the range of $100 \mathrm{~V}_{\mathrm{ac}}$ to $250 \mathrm{~V}_{\mathrm{ac}}$.

These characteristics can be adjusted by changing the design parameters. The maximum detectable current is equivalent to the Faraday-rotation angle of $45 \mathrm{deg}$ and is $100 \mathrm{kA}$. The minimum detectable current is decided by the signal to noise (SN) ratio of the output voltage. Therefore, it can be adjusted by changing the number of turns of the sensing fiber and changing the frequency response band of the signal processing circuit. The response time is mainly decided by the response of the signal processing circuit.

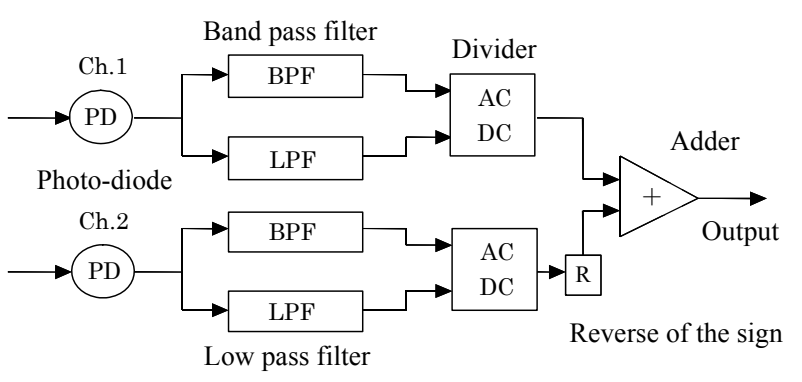

Fig. 3 Block diagram of the signal processing circuit.

\subsection{Key techniques}

Through the process of researches and developments of optical fiber current sensors for a long time, the stability of performances, simplification of structures, and reduction of manufacturing costs have been recognized as common subjects for the widespread of the practical application of the technology. In the developed sensing technology, the subjects are achieved with the following key techniques:

(1) Special fiber for the sensing element

When the optical fiber made from the fused silica is used as the Faraday sensor fiber, the polarization of light may be affected by stress due to the photo-elastic effect in the fiber. If this phenomenon occurs, it becomes difficult to distinguish between the change in the polarization caused by the Faraday-effect and that caused by the photo-elastic effect.

In this development, this problem was solved by using the special sensing fiber made from flint glass of the very small photo-elastic constant, which was developed in cooperation by TEPCO and HOYA [6]. The photo elastic constant of the core of the fiber $\left(0.45 \times 10^{-9} \mathrm{~cm}^{2} / \mathrm{kg}\right)$ is less than $1 / 700$ of that of the fused silica. Farther, the Verdet's constant of the flint glass $(0.23 \mathrm{deg} / \mathrm{kA}$, wavelength: $1550 \mathrm{~nm})$ is about 6 times greater than that of the fused silica. The transmission loss of the fiber is less than $1.3 \mathrm{~dB} / \mathrm{m}$ (wavelength: $1550 \mathrm{~nm}$ ).

(2) Stable optical system

As a different problem related to the polarization 
of light, a phenomenon is known that the polarization plane of light transmitted through the sensing fiber rotates depending on the shape of the curve of the fiber [8]. The rotation angle is equal to the line integral of the torsional rate along the curve of the fiber. In this occasion, it also becomes difficult to distinguish between the rotation of the polarization plane caused by the Faraday-effect and that caused by the geometric effect. To solve this problem, a method of round trip light transmission using a mirror is used, from the knowledge that the effect is reciprocal. With this constitution, the rotation of the polarization plane by the geometric effect is canceled.

(3) Simple signal processing

A simple signal processing method named "averaging of modulations" is applied [9]. By using the method, the drift of the output value caused by various origins are easily compensated, and the stable output can be obtained. The causes of the drift includes the changes in the light source intensity, the changes in the light transmission loss in the path from the light source to the photo-detectors, the optical bias shift caused by the changes in polarization properties of optical components. Further, by using this processing method, noises of the detecting light intensity caused by, for example, ripples of the light source is reduced.

(4) Compact sensing head

For applying the sensing head to the electric power apparatus, it should be compact and durable to withstand sever environmental conditions such as the wide temperature range. To meet the requests, a sensing-head composed of the sensing fiber, a mirror, the signal transmission fiber, and an optical box (including crystals, a lens and other components) was developed [4].

For the development of this sensing head, the manufacturing process of optical components for the signal transmission system was applied. Special features of this module are the simple structure, small and stable insertion loss, stable polarization properties, and mass production.

\subsection{Benefits}

Before introducing application systems, benefits of utilizing the developed current sensing devices to the power facility are summarized here. In comparison with that using magnetic induction type current transformers, the benefits are as follows:

\section{(1) Installation}

Accurate measurement can be done by winding the flexible sensor fiber simply around the current conductor. This is due to, as mentioned before, the effect of using the low birefringence sensing fiber and the reflection scheme of the optical system.

(2) Electric insulation

Electric insulation can be secured easily when the sensor head is installed to the high voltage power apparatus. So, the sensing head including the attachment is compact and light.

(3) Signal transmission

Due to the long wavelength light transmission with the silica fiber, the device is immune to electro-magnetic induction noise, and also long distance signal transmission is possible. Sites for setting electronics can be selected freely without the restriction of the transmission distance.

(4) Measurement range

Measurement of the large current, which flows in the accidental condition of a power system, can be possible because the sensor does not suffer the magnetic saturation. Measurement of the high frequency current is also possible.

(5) Little influence on current to be measured

Accurate measurement of the current whose power source is very small can be done because the current is not influenced very much by the setting of the sensing device near the conductor.

\section{Applications}

Taking note of the benefits mentioned above, several kinds of application systems of the sensing technology for the electric power facility were developed, in cooperation between Tokyo Electric 
Power Company (TEPCO), to which the author belonged and electric power device producers. Some representative examples of them are introduced below.

\subsection{Fault section locating system for underground power transmission lines}

(1) Outline of the system

In a power transmission line in which the underground cable is incorporated with overhead lines, when a fault occurs, it is necessary to detect the fault to decide the location whether it is in the cable section or in the overhead line sections. For the purpose, a fault section locating system using the optical fiber current sensors was developed, by a joint work between TEPCO, Takaoka Electric MFG. Co., and Kansai Electric Power Company $[10,11]$.

Figure 4 shows the system configuration. At both ends (A and B) of the underground cable, optical fiber current sensors are installed to the cable. The sensors are capable of detecting the zero phase fault current. The signal light from the sensor head whose intensity is modulated by the fault current is transmitted, by the signal transmission fibers, to the detection panel set at a substation. At the detection panel, the section where the fault occurs is decided from the difference between the measured current values at the points $\mathrm{A}$ and $\mathrm{B}$, and the decision is the output signal.

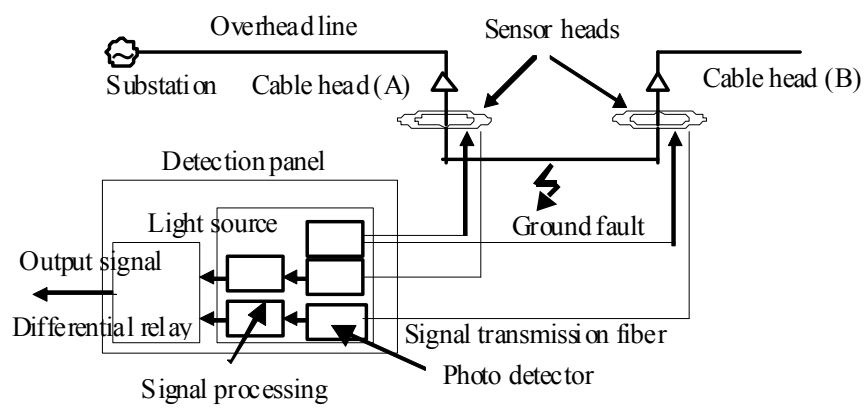

Fig. 4 Fault section locating system for underground power transmission lines.

(2) Practical application

Figure 5 shows a sensing head for the practical use attached to a $66-\mathrm{kV}$ underground cable in a pit underground. In the figure, the reflection type sensor encircles around all the 3 phases of the cables, and therefore the sensor detects the zero phase fault current (sum of the current of 3 phases) precisely. Since 2004, the new systems have been applied

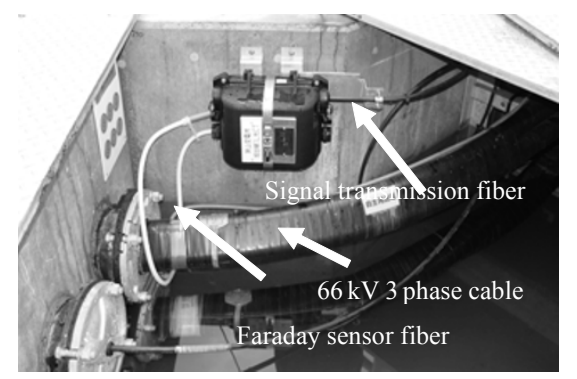

Fig. 5 Sensor head attached to a $66-\mathrm{kV}$ underground power cable of 3 phases. practically in Tokyo Electric Power Co., Kansai Electric Power Co., and some other Power companies in Japan.

(3) Application to overhead cable lines

The system described above can be applied to other types of the power apparatus, with some customizing. As an example, Fig. 6 shows the field test equipment of the system being applied to a $22-\mathrm{kV}$ overhead distribution cable line [12].

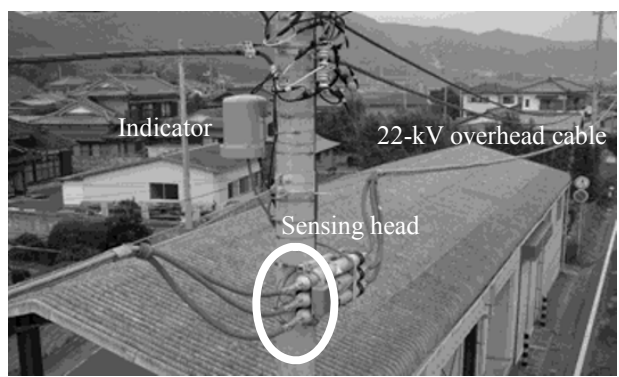

Fig. 6 Application of the fault section location system to a $22-\mathrm{kV}$ overhead cable line. 


\subsection{Fault point locating system for underground power transmission lines}

(1) Outline of the system

For the purpose of identifying spots of faults in underground cable transmission lines, a fault "point" locating system using the sensing technology was developed by a joint project between TEPCO, Fujikura Ltd., and Toko Electric Corp. [10, 13].

Figure 7 shows a configuration of the system. The system consists of two optical fiber current sensors attached at both ends of the power cable, two local stations, a master station, and signal transmission lines among them. When a fault occurs, each of the optical fiber current sensors detects the surge current that arrives from the fault point, and it transmits the detection signal to the local station.
Then, each of the local stations measures the arrival time of the surge precisely with the GPS clock, and the local station sends the data to the master station. The master station decides the fault point from the difference in the arrival time data sent from the local stations. The velocity of the surge transmission is nearly $60 \%$ of the speed of light in the space, and the shortest rise-time of the surge current is about 1 micro second. Therefore, to detect such fast phenomenon of the surge current, the frequency response band of the current sensor is designed to be wideband $(250 \mathrm{kHz})$.

Figure 8 shows a sensing head wound around the $275-\mathrm{kV}$ oil filled power cable, when the developed system was tested in the field. From the figure, it becomes known that attaching the sensing head to an existing cable is easy.

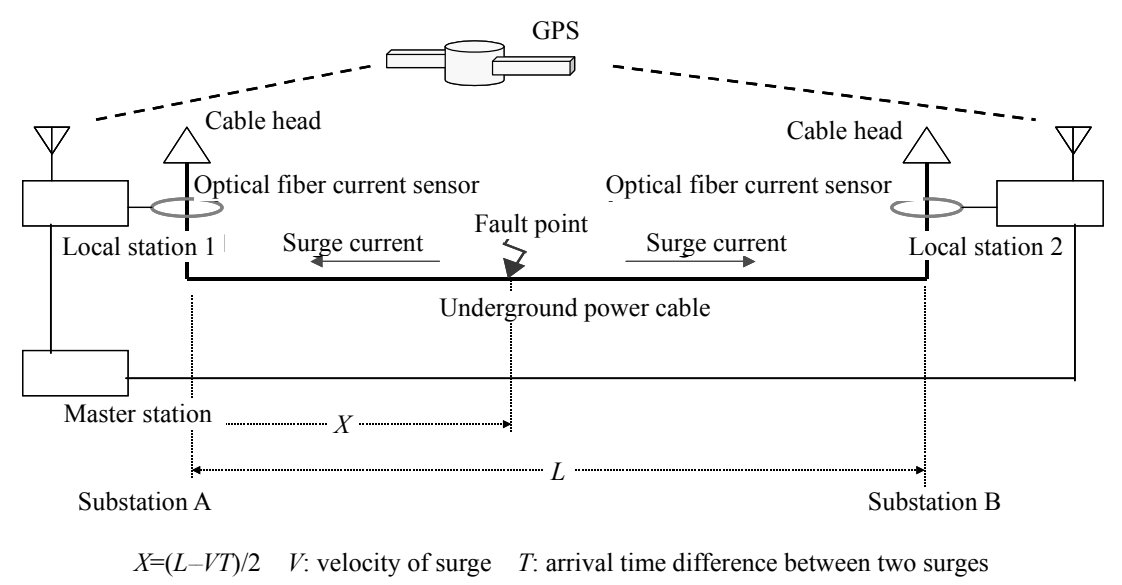

Fig. 7 Fault point location system for underground power transmission lines.

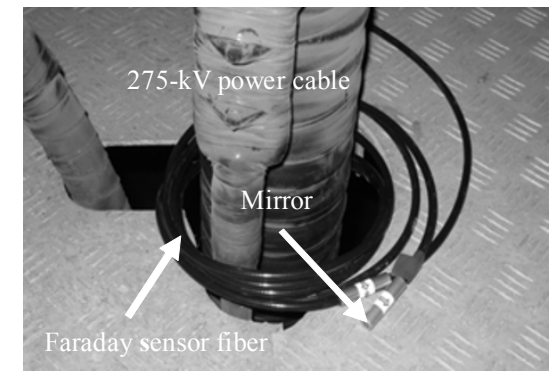

Fig. 8 Faraday sensor fiber wound around a $275-\mathrm{kV}$ underground oil filled (OF) power cable.

(2) Application

By a field test for the fault location using a
$275 \mathrm{kV}, 15-\mathrm{kmcable}$ line, it became clear that the maximum location error of the system is less than $50 \mathrm{~m}$, and the locating accuracy is conformed to the required value sufficiently [13]. After the evaluation of the test results, since 2007, the system has been applied practically for $275-\mathrm{kV}$ underground lines of TEPCO. Figure 9 indicates a sensing head for the practical use attached to a $275-\mathrm{kV}$ pipe-type oil filled (POF) cable. 


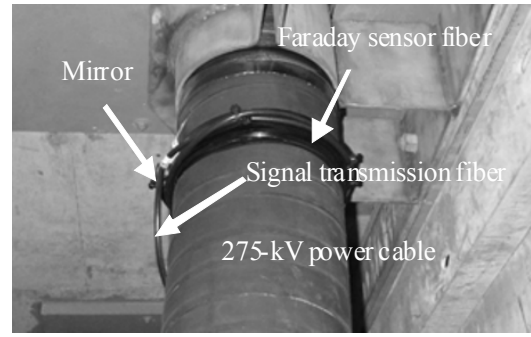

Fig. 9 Sensing head practically applied to the $275-\mathrm{kV}$ POF power cable.

\subsection{Current measurement with a portable type device [14]}

Figure 10 shows an operator who is measuring the load current of a power cable using a portable type device. The sensor fiber is wound around the cable and is connected to the main box at the left

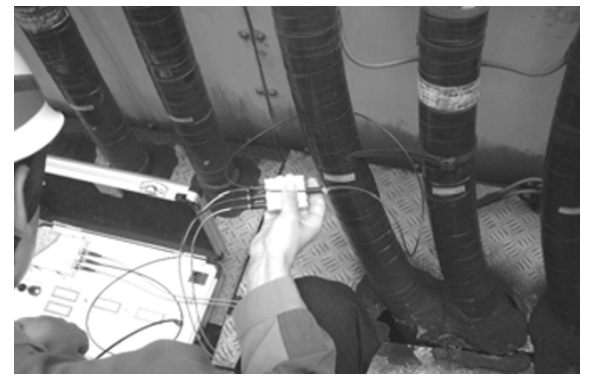

Fig. 10 Current monitoring of a $6.6-\mathrm{kV}$ power cable using a reflection type sensor. side of the picture. The measurement value is indicated on the box. The signal output can be connected to other devices such as the oscilloscope. The main box is equipped with the storage buttery power source, and the device can operates at a place where the AC power source is not supplied.

\section{Actual results of practical applications}

The developed current sensing technology has been transferred, by TEPCO to which the author belongs, to some electric power apparatus producers and some measurement device producers that were interested in the utilization of the technology. By the producers, new application systems utilizing the sensors have been developed, and some of them are distributed as products and are already applied practically in the fields $[20,21]$. Table 1 lists such products which are applied practically. The list includes applications introduced in the former Section 3, of which the author participated in the development. The number of the sensing heads practically applied in the fields was nearly 1200 , by March 2012.

Table 1 List of practical applications.

\begin{tabular}{l|c|c}
\hline \multicolumn{1}{c|}{ Products } & Application field & First application \\
\hline Fault locating system & & References \\
\hline Section locating system for power lines & Electric power facility & 2004 \\
\hline Point locating system for power lines & Electric power facility & 2007 \\
\hline Section locating system for substations & Electric power facility & 1999 \\
\hline Testing of inverter devices & Vehicle manufacturing & 2006 \\
\hline Harmonic current monitoring & Railroad system & 2006 \\
\hline Portable current measurement device & Laboratories & {$[10,13]$} \\
\hline Lightning current monitoring, others & Not announced & 2004 \\
\hline \multicolumn{2}{|c|}{ Number of the sensing heads practically applied: 1200} \\
\hline
\end{tabular}

"First application" means " year of the first practical application".

\section{Summary}

This paper describes the development and application of a fiber-optic current sensing technology, carried out by the author and his colleagues in TEPCO, in cooperation with several companies.

The developed sensing device can be installed easily to the existing power apparatus by winding the flexible sensing fiber around the current conductor, and also, it has stable measurement characteristics. These excellent features are achieved 
by applications of the following key techniques:

(1) Special low birefringence sensing fiber.

(2) Reflection type system for stable characteristics.

(3) Simple signal processing for stable characteristics.

(4) Compact sensing head of simple structure.

In this paper, as examples of the practical use of the sensing technology, "fault section" and "fault point" locating systems for underground transmission lines are introduced. Adding to these examples, various application systems utilizing the sensors have been developed by several manufactures, and some of them are already applied practically. The total number of the sensing heads practically applied in the fields is nearly 1200 by the end of March 2012.

An important present objective of the sensing technology is the application to the protective relaying systems of the electric power facility. Directing to the aim, the author is studying the sensing technique continuously $[5,19]$.

\section{Acknowledgment}

The author would like to thank all people who took part in the development and application of the technology described in this paper, who acted in TEPCO or in other companies, for their contributions to the fruitful results.

Open Access This article is distributed under the terms of the Creative Commons Attribution License which permits any use, distribution, and reproduction in any medium, provided the original author(s) and source are credited.

\section{References}

[1] S. Saito, J. Hamasaki, Y. Fujii, K. Yokoyama, and Y. Ohno, "Development of the laser current transformer for extra-high-voltage power transmission lines," IEEE Journal of Quantum Electronics, 1967, 3(11): 589-597.

[2] A. Rapp and H. Harms, "Magneto-optical current transformer," Applied Optics, 1980, 19(22): 3729-3745.

[3] K. Kurosawa, K. Yamashita, T. Sowa, and Y. Yamada, "Flexible fiber Faraday effect current sensor using flint glass fiber and reflection scheme," IEICE Transactions on Electronics, 2000, 83(3): 326-330.

[4] K. Kurosawa, Y. Hiroki, and K. Shirakawa, "Compact and flexible fiber current sensors," in Proc. 30th Meeting on Lightwave Sensing Technology, no. LST30-19, pp. 133-140, 2002 (in Japanese).

[5] R. Kondo and K. Kurosawa, "A method for improving temperature dependence of an optical fiber current sensor," IEEJ Transactions on Power and Energy, 2010, 130(4): 414-420 (in Japanese).

[6] K. Kurosawa, S. Yoshida, and K. Sakamoto, "Polarization properties of the flint glass fiber," Journal of Lightwave Technology, 1995, 13(7): 1378-1384.

[7] F. Briffod, L. Thevenaz, P. Nicati, A. Kung, and P. Robert:, "Polarimetric current sensor using an in-line faraday rotator," IEICE Transactions on Electronics, 2000, E83-C(3): pp. 331-335.

[8] J. N. Ross, "The rotation of the polarization in low birefringence mono-mode optical fibers due to geometric effect," Optical and Quantum Electronics, 1984, 16: 455-461.

[9] K. Kurosawa, S. Yoshida, K. Sakamoto, and T. Yamashita, "A current sensor using the Faraday effect in optical fiber manufactured from flint glass," Electrical Engineering in Japan, 1997, 118(3): 22-38.

[10] S. Nasukawa, R. Kondo, K. Kurosawa, T. Yamaguchi, K. Amano, and T. Yamada, “Application of optical fiber current sensors to underground cables," in 7th JICABLE Conf., Session A.5, Diagnostics, vol. 2, no. A5.5, 2007.

[11] M. Kayaki, T. Hirata, K. Kurosawa, R. Kondo, T. Yamada, and E. Itakura, "Development of fault detection system using wave division multiplexing transmission of optical fiber current sensor," IEEJ Transactions on Power and Energy, 2010, 130(1): 49-54 (in Japanese).

[12] K. Kurosawa, K. Shirakawa, H. Saito, E. Itakura, T. Sowa, Y. Hiroki, et al., "Field tests of a fault Section locating system for power transmission cable lines using optical fiber current sensors," in Technical Digest: 16th International Conference on Optical Fiber Sensors, pp. 316-319, 2003.

[13] K. Kurosawa, R. Kondo, S. Nasukawa, T. Yamaguchi, and K.Amano, "Development of fault point locating system for underground transmission lines using optical fiber current sensors," Electrical Engineering in Japan, 2012, 178(1): 21-28.

[14] K. Kurosawa, K. Shirakawa, and T. Kikuchi, "Development of optical fiber current sensors and their applications," in Transmission and Distribution Conference and Exhibition: Asia and Pacific, Dalian, China, 2005.

[15] E. Itakura, Y. Naraki, and T. Hirano, "Fault section locating system using optical CTs for substations," Takaoka Review, 2005, 50(1): 10-13 (in Japanese). 
[16] T. Kaoru, S. Hiroyuki, and T. Katsuya, "Development of a current evaluation methodology using optical fiber sensor for designing compact hybrid vehicle inverters," in Proc. FISTA-2008, no. F2008-06-050, 2008.

[17] N. Miyazawa, "Optical fiber current sensors and their application products," Denki-Genba-Gijutsu, 2007, 46(54): 29-30 (in Japanese).

[18] "Optical current sensor," Adamant Kogyo Co., Ltd. (available from http://www.adamant-kogyo.com/ japanese/products/current-sensor/index.html).

[19]R. Kondo, K. Kurosawa, E. Itakura, T. Kotake, and Y.
Shiino, "Development of an optical fiber current sensor with improved output stability against disturbances to the signal transmission fiber line," in International Conf. CMD 2010, Tokyo, no. B7-5, pp. 419-422, 2010.

[20] K. Kurosawa, "Present status of application of optical fiber current sensors," The Journal of The Institute of Electrical Engineers of Japan, 2010, 130(10): 672-675 (in Japanese).

[21] K.Kurosawa, "Development of fiber-optic current sensing technology for electric power systems," in Proc. SPIE, vol.8421, pp. 84210O, 2012. 